\title{
Prevalence and Pattern of Abnormal Pap Smear among Pregnant Women Attending Antenatal Clinic in a Missionary Hospital in Abakaliki, Southeast Nigeria
}

\author{
Kenneth Chinedu Ekwedigwe ${ }^{1 *}$, Paul Olisaemeka Ezeonu1, Felix Edegbe ${ }^{2}$, Chidi Esike ${ }^{1}$, \\ Anthony Tagbo Agbata1, Chukwuemeka Ikechi Ukaegbe ${ }^{1}$, Okechukwu Bonaventure Anozie1, \\ Obiorah Godfrey Asiegbu', Maradona Isikhuemen ${ }^{3}$
}

\author{
${ }^{1}$ Department of Obstetric \& Gynaecology, Federal Teaching Hospital, Abakaliki, Nigeria \\ ${ }^{2}$ Department of Pathology, Federal Teaching Hospital, Abakaliki, Nigeria \\ ${ }^{3}$ Department of Obstetrics \& Gynaecology, University of Benin Teaching Hospital, Benin, Nigeria \\ Email: *ekwedigwe@yahoo.com
}

How to cite this paper: Ekwedigwe, K.C., Ezeonu, P.O., Edegbe, F., Esike, C., Agbata, A.T., Ukaegbe, C.I., Anozie, O.B., Asiegbu, O.G. and Isikhuemen, M. (2018) Prevalence and Pattern of Abnormal Pap Smear among Pregnant Women Attending Antenatal Clinic in a Missionary Hospital in Abakaliki, Southeast Nigeria. Open Journal of Obstetrics and Gynecology, 8, 728-740. https://doi.org/10.4236/ojog.2018.88077

Received: June 6, 2018

Accepted: July 23, 2018

Published: July 26, 2018

Copyright (c) 2018 by authors and Scientific Research Publishing Inc. This work is licensed under the Creative Commons Attribution International License (CC BY 4.0).

http://creativecommons.org/licenses/by/4.0/ cC) $\underset{\mathrm{EY}}{\mathrm{EY}}$ Open Access

\begin{abstract}
BACKGROUND: Cervical cancer is the most common type of cancer affecting the genital tract among women in developing countries. Screening programmes have been well talked about in Nigeria, but they are not well organized. Hence, the incidence of cervical cancer does not appear to be reducing. A possible way of solving this problem is by doing an opportunistic pap smear among women attending antenatal clinics, since a good number of women do access antenatal care. OBJECTIVES: To determine the prevalence, knowledge, awareness, practice, risk factors and pattern of Pap smear among women attending antenatal clinic in Mile 4 hospital, Abakaliki. METHOD: This is a cross-sectional study carried out at the antenatal clinic of Mile 4 Hospital, Abakaliki, Nigeria. A total of 110 consecutive pregnant women who fulfilled the inclusion criteria and have given their consent were recruited into the study at the time of their first prenatal (booking clinic) visit for antenatal care. Data was collected using a questionnaire. Conventional Papanicolaou smear was taken using the standard procedure. The cytopathologic findings were documented in the questionnaire. RESULTS: Out of the 110 pregnant women who had cervical cytology by Pap smear, 7 had pre-invasive cervical lesion, giving a prevalence rate of 6.3\%; 5 (71.4\%) were low-grade squamous intraepithelial lesion (LGSIL) while $2(28.6 \%)$ were high-grade squamous intraepithelial lesion (HGSIL). Fifty women (45.5\%) had negative smears. Inflammatory smears were seen in 50 women (45.5\%). Insufficient smear was seen in 3 women $(2.7 \%)$. Fifty-six women had knowledge about cervical can-
\end{abstract}


cer $(50.9 \%)$, while thirty-six women $(32.7 \%)$ were aware of a screening program for cervical cancer and only 2 women $(1.8 \%)$ had been screened in the past. Hence, from this study, the population screening rate was approximately $2 \%$. The risk factors were age of coitarche $<15$ years, number of sexual partners, previous history of sexual transmitted infection, genital warts, human immune deficiency virus and use of contraceptives. CONCLUSION: The pap-smear findings among pregnant women in Abakaliki, Nigeria showed that the pre-invasive lesion of the cervix is relatively common. Pap smear should be made routine for all pregnant women.

\section{Keywords}

Pregnancy, Pap Smear, Cervical Cancer

\section{Introduction}

Cervical cancer is the most common type of cancer affecting the genital tract among women in developing countries and Nigeria is not an exception. Worldwide, 528,000 cases are recorded every year and 266,000 women die from cervical cancer [1]. In Nigeria, there are 14,089 cervical cancer cases recorded and 8240 cervical cancer deaths annually [2]. In the last fifty years, the morbidity and mortality of cervical cancer has drastically reduced in the developed countries because of effective screening programmes [3]. However, the reverse is the case in the developing countries due to the lack of screening programmes [3].

Preinvasive cervical lesions are precursor lesions for cervical carcinoma. These lesions begin with infection of the metaplastic epithelium of the transformation zone of the cervix with one or more of the high-risk types of human papillomavirus (HPV) [4]. At least $1 \%$ of the population of childbearing women screened annually for cervical cancer will be diagnosed with CIN [4]. Since these precursor lesions can be detected by screening and are amenable to treatment before it becomes invasive, pregnancy offers an excellent opportunity for screening. Most cervical abnormalities in pregnancy reported in literature are detected from the antenatal care in developed countries where such screening is offered [4]. In the United States, about 2 - 3 million abnormal Pap smears are diagnosed each year and $5 \%-13 \%$ of these are detected in pregnant women [4]. It therefore poses an opportunity for us to provide cervical cancer screening that should not be missed.

Several risk factors have been associated with cervical intraepithelial neoplasia (CIN) and subsequent development of an invasive disease. These risk factors are known to be associated with HPV infection [5]. These risk factors include multiple partners, history of sexually transmitted infection (STD), smoking, infection with human immunodeficiency virus, immunesuppression, long term contraceptive pills, low socioeconomic class, early coitarche etc., but the main cause of cervical cancer was infection with Human Papilloma Virus (HPV) [2] [4] [5] [6]. Given the increasing incidence of HPV infection and CIN in young women, 
the beginning of pregnancy may present a window of opportunity for all pregnant women who do not take part in cervical screening program to undergo cytological test [4].

The natural history of cervical neoplasia during pregnancy and postpartum period has been examined in several studies. Some studies revealed pregnancy as having no effect on cervical neoplasia, whereas others have reported higher regression rates of cervical neoplasia in the postpartum period compared with spontaneous regression of neoplasia for non-pregnant women [7]. There are few published data on the prevalence of CIN in pregnancy in Nigeria and its other African countries. From the studies cited from different geographical regions of Nigeria, it is evident that most of the studies carried out are on non-pregnant women, women with HIV, and other high-risk women. There are few studies generally on preinvasive cervical lesion in pregnancy in developing countries [4].

The fear of causing morbidity in pregnancy such as: infection, inducing heavy bleeding and the risk of an iatrogenic miscarriage are the concerns. A study in Zaria, Northern Nigeria, on the prevalence and course of preinvasive cervical lesions during pregnancy showed the prevalence of cervical dysplasia of $6 \%$ [4]. However, prevalence rate of $4.8 \%$ was observed in a retrospective collaborative study over a 5-year period on non-pregnant women in Zaria [4].

This study aimed to determine the prevalence and pattern of pre-invasive cervical lesion in pregnancy.

\section{Materials and Methods}

\subsection{Study Area}

The study was conducted at Mile 4 hospital, Abakaliki, Ebonyi State. Mile 4 hospital is one of the major providers of health care in Abakaliki. It is a missionary hospital which provides care mainly to pregnant women and children. Ebonyi state is primarily an agricultural region.

\subsection{Study Population}

Study population comprises of pregnant women who are attending antenatal clinic at Mile 4 hospital, Abakaliki.

\subsection{Inclusion Criteria}

Pregnant women who are attending antenatal clinic in Mile 4 hospital, Abakaliki and who gave their consent for the study.

\subsection{Exclusion Criteria}

Patients who are not willing to give consent. Acutely ill patients. Coitus over the past 48 hours. Vaginal douching over the past 48 hours. Women who were previously treated for preinvasive cervical lesion in the past. Women who were bleeding at the time of contact. Parturients in labour and delivery. 


\subsection{Study Design}

Cross-sectional.

\subsection{Ethical Consideration}

Permission for this study was obtained from the Ethical Committee of Mile 4 hospital. Voluntary informed consent was obtained from participants.

\subsection{Sample Size Determination}

The formula below was used to calculate the sample size.

$$
n=Z^{2} p q / d^{2}
$$

where;

$$
\begin{aligned}
& n=\text { minimum sample size; } \\
& Z=\text { standard normal deviation or } z \text {-score }=1.96 ; \\
& p=\text { prevalence of abnormal pap smear from a study done in Zaria, Nigeria } \\
& (6 \%) ; \\
& Q=1-\mathrm{p} ; \\
& d=\text { level of accuracy }=0.05 ; \\
& 1.96^{2} \times 0.06 \times 0.94 / 0.05^{2}=87
\end{aligned}
$$

To make provisions for unreturned questionnaires, $10 \%$ attrition was incorporated bringing the minimum number of administered questionnaire to be 96 .

However 110 respondents were involved in this study.

\subsection{Study Duration}

This study was conducted between 1st of February and 1st of March 2018.

\section{Method of Sampling}

Convenient sampling method.

\subsection{Pre-Testing}

Pre-testing was done among women attending regular cervical cancer screening clinic at the National Obstetric Fistula Centre, Abakaliki. This permitted modification of the questions to suit the respondents. The pre-testing was done on 15 patients and that gave a prevalence rate of $6.7 \%$.

\subsection{Method of Data Collection}

One hundred and ten (110) pregnant women participated in this study irrespective of parity. Data collection was done with the aid of semi-structured questionnaires containing open and close ended questions on socio-demographic data, knowledge of Pap smear, attitude towards routine pap smear in pregnancy, risk factors and results. The questionnaire was designed by the authors using questionnaires on previous studies. It has thirty-six items. It was interviewer administered. See Appendix 1. 
The women were again counselled properly on the procedure to be carried out. The participants were placed in the lithotomy position, and a disposable plastic sterile bivalve speculum was inserted into the vagina to expose the cervix. The cervix was visualized using an anglepoise lamp to identify the squamo-columnar junction. Excess mucus was cleaned using a cotton swab. Ayres spatula was used to scrape cells from the squamo-columnar junction of the transitional zone of the cervix by rotating it through $360^{\circ}$. The cells were smeared on two glass slides and immediately fixed in $95 \%$ ethanol. Pathology request forms were appropriately filled stating clearly the pregnancy state of the women and their estimated gestational age. The patient's serial and telephone numbers were clearly written on the request forms to facilitate follow-up. The sample containers along with the request forms were then taken to the pathology laboratory for slide preparation. The smears were stained using the Papanicolaou staining technique. A trained cytopathologist interpreted all the slides. The Bethesda system of classification was used in grading preinvasive cervical lesion [8].

\subsection{Data Analysis}

The results of the investigation were recorded in the pro forma. Data from questionnaire was collated and entered into a spread sheet for analysis using the Statistical Package for Social Sciences (SPSS) Version 21. Descriptive and summary statistics and cross-tabulation were used to describe the data in relation to relevant variable.

\section{Result}

One hundred and ten (110) pregnant women participated in this study and their findings were as analyzed in the tables below (Table 1).

The age range of the respondents is between 15 - 44 years. The highest age range from this study was between 25 - 29 years of age (41.8\%), while the lowest was between 40 - 44 years of age (1.8\%). Most of the respondents were multipara $53(48.2 \%)$. Most women are Igbos 109 (99.1\%). Majority of these women are from Ebonyi state $97(88.2 \%)$. Majority of them had secondary level of education $60(54.5 \%)$, while $2(1.8 \%)$ had no formal education. Majority of the women are married $101(91.8 \%)$ while $8(7.3 \%)$ are single and $1(0.9 \%)$ is separated. Majority are traders $33(30 \%)$ while $27(24.5 \%)$ were unemployed (Table 2$)$.

Majority of the respondents were on their $3^{\text {rd }}$ trimester 65 (59.1). This is followed by second trimester gestation which was 41 (37.3). The least was first trimester which was 4 (3.6\%) (Table 3).

Almost half of the respondents $54(49.1 \%)$ have not heard of cervical cancer before. Majority of the respondents 74 (67.3\%) were not aware of cervical cancer screening, while majority of those that were aware 21 (19.1\%) were told in the hospital (Table 4).

Only 2 patients (1.8\%) were screened in the past. About 108 (98.2\%) have not been screened in the past. Majority of those that were not screened in the past 76 
(99.1\%) said they were not aware. Majority of the women 35 (31.8\%) agreed to recommend the procedure to other women (Table 5).

Most of the women $82(74.5 \%)$ had coitarche before the age of twenty. Three women $(2.7 \%)$ had genital warts. About 46 (41.8\%) women had STI in the past which was treated. About 42 (38.2\%) of the respondents had history and treatment of STI in their partners. Majority of the women 83 (75.5\%) do not use contraceptives. Two women (1.8\%) tested positive for HIV. Few women 3 (2.7\%) use tobacco (Table 6).

On gross examination, majority of the women 104 (94.5\%) had healthy looking cervix. Five women (4.5\%) had growth on their cervix, while one $(0.9 \%)$ had hyperemic cervix (Table 7).

The Pap smear result showed insufficient smear in 3 women $(2.7 \%)$, Inflammatory smear in 50 women (45.5\%) and negative smear in 50 women $(45.5 \%)$ and preinvasive lesion in 7 women (6.3\%) that is LSIL 5 (4.5\%), HSIL 2 (1.8\%) (Table 8).

The cytologic grading showed no lesion in 103 women $(93.7 \%)$ and positive lesion in 7 women (6.3\%) (Table 9).

This table analyzed the distribution of the preinvasive lesion. The low grade squamous intraepithelial lesion LSIL was found in 5 women (71.4\%), while the high grade intraepithelial lesion was found in 2 women (28.6\%).

Table 1. Socio-demographic variables.

\begin{tabular}{|c|c|c|c|}
\hline & & Frequency & Percent \\
\hline & $15-19$ & 4 & 3.6 \\
\hline & $20-24$ & 23 & 20.9 \\
\hline & $25-29$ & 46 & 41.8 \\
\hline \multirow[t]{6}{*}{ AGE } & $30-34$ & 24 & 21.8 \\
\hline & $35-39$ & 11 & 10.0 \\
\hline & $40-44$ & 2 & 1.8 \\
\hline & Total & 110 & 100.0 \\
\hline & ${ }^{*}$ NULLIPARA & 29 & 26.4 \\
\hline & ${ }^{\star P R I M I P A R A}$ & 22 & 20.0 \\
\hline \multirow[t]{4}{*}{ PARITY } & MULTIPARA & 53 & 48.2 \\
\hline & GRAND MULTIPARA & 6 & 5.5 \\
\hline & Total & 110 & 100.0 \\
\hline & IGBO & 109 & 99.1 \\
\hline \multirow[t]{2}{*}{ TRIBE } & HAUSA & 1 & .9 \\
\hline & Total & 110 & 100.0 \\
\hline \multirow[t]{2}{*}{ LEVEL OF EDUCATION } & PRIMARY & 6 & 5.5 \\
\hline & SECONDARY & 60 & 54.5 \\
\hline
\end{tabular}




\section{Continued}

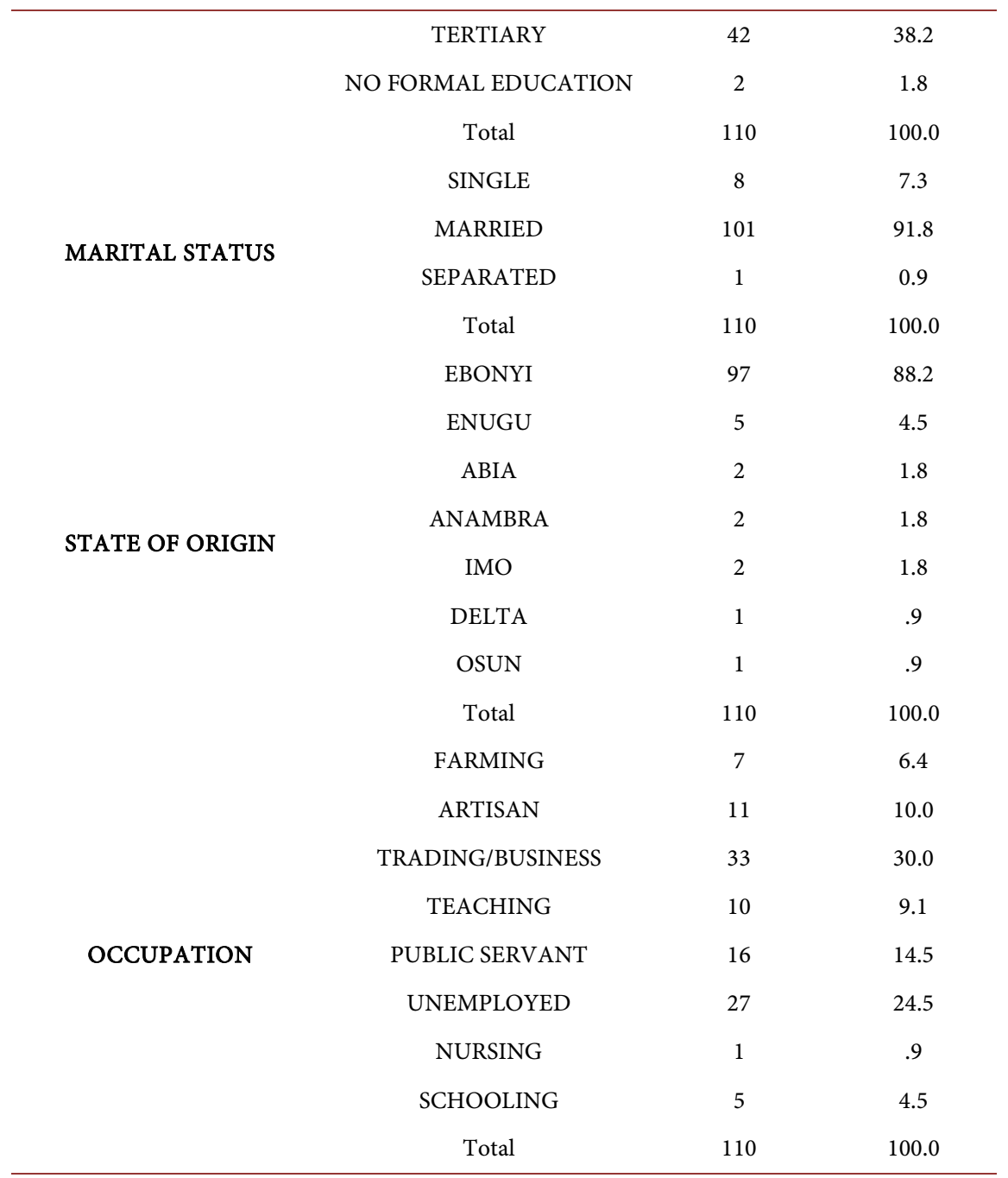

*Nulliparity means women who have not carried pregnancy to the age of viability before irrespective of the outcome. (Age of viability from this study is 28 completed weeks gestation). While Primiparity are women who have carried pregnancy to the age of viability once, irrespective of the outcome.

Table 2. The trimester table.

\begin{tabular}{ccc}
\hline TRIMESTER & Frequency & Percent \\
\hline 1ST TRIMESTER & 4 & 3.6 \\
2ND TRIMESTER & 41 & 37.3 \\
3RD TRIMESTER & 65 & 59.1 \\
Total & 110 & 100.0 \\
\hline
\end{tabular}

Table 3. Knowledge and awareness of cervical cancer.

\begin{tabular}{cccc}
\hline & & Frequency & Percent \\
\hline HAVE YOU HEARD OF & YES & 56 & 50.9 \\
CERVICAL CANCER & NO & 54 & 49.1 \\
& Total & 110 & 100.0 \\
\hline
\end{tabular}




\section{Continued}

\begin{tabular}{cccc}
\hline & YES & 36 & 32.7 \\
AWARENESS OF CERVICAL & NO & 74 & 67.3 \\
CANCER SCREENING & Total & 110 & 100.0 \\
& NOT AWARE & 73 & 66.4 \\
& HOSPITAL & 21 & 19.1 \\
SOURCE OF AWARENESS & FRIEND & 1 & .9 \\
& MEDIA & 13 & 11.8 \\
& SCHOOL & 2 & 1.8 \\
\hline
\end{tabular}

Table 4. Practice of cervical screening.

\begin{tabular}{|c|c|c|c|}
\hline & & Frequency & Percent \\
\hline \multirow{6}{*}{$\begin{array}{l}\text { HAVE YOU EVER BEEN } \\
\text { SCREENED }\end{array}$} & YES & 2 & 1.8 \\
\hline & NO & 108 & 98.2 \\
\hline & Total & 110 & 100.0 \\
\hline & COST & 3 & 2.7 \\
\hline & $\begin{array}{c}\text { I DON'T KNOW WHERE } \\
\text { TO DO IT }\end{array}$ & 20 & 18.2 \\
\hline & IT'S NOT NECESSARY & 5 & 4.5 \\
\hline \multirow[t]{5}{*}{ IF NOT WHY } & NO TIME & 4 & 3.6 \\
\hline & I'M NOT AWARE & 76 & 69.1 \\
\hline & I'VE BEEN SCREENED & 2 & 1.8 \\
\hline & Total & 110 & 100.0 \\
\hline & & Frequency & Percent \\
\hline \multirow{4}{*}{$\begin{array}{l}\text { WILL YOU RECOMMEND } \\
\text { THE PROCEDURE TO } \\
\text { OTHER WOMEN }\end{array}$} & YES & 35 & 31.8 \\
\hline & NO & 1 & .9 \\
\hline & MAYBE & 6 & 5.5 \\
\hline & NON-RESPONDENTS & 68 & 61.8 \\
\hline \multicolumn{2}{|c|}{ Total } & 110 & 100.0 \\
\hline
\end{tabular}

Table 5. Table of risk factors.

\begin{tabular}{cccc}
\hline & & Frequency & Percent \\
\hline \multirow{2}{*}{ GENITAL WARTS } & YES & 3 & 2.7 \\
& NO & 107 & 97.3 \\
& Total & 110 & 100.0 \\
HISTORY AND TREATMENT OF STI & & Frequency & Percent \\
IN THE PAST & YES & 46 & 41.8 \\
& NO & 64 & 58.2 \\
& Total & 110 & 100.0
\end{tabular}




\section{Continued}

\begin{tabular}{|c|c|c|c|}
\hline \multirow{5}{*}{$\begin{array}{l}\text { HISTORY AND TREATMENT OF STI } \\
\text { IN THE PARTNER }\end{array}$} & YES & 42 & 38.2 \\
\hline & NO & 68 & 61.8 \\
\hline & Total & 110 & 100.0 \\
\hline & & Frequency & Percent \\
\hline & YES & 27 & 24.5 \\
\hline \multirow[t]{4}{*}{ USE OF CONTRACEPTION } & NO & 83 & 75.5 \\
\hline & Total & 110 & 100.0 \\
\hline & & Frequency & Percent \\
\hline & NEGATIVE & 96 & 87.3 \\
\hline \multirow[t]{2}{*}{ HIV POSITIVE } & POSITIVE & 2 & 1.8 \\
\hline & Total & 98 & 89.1 \\
\hline \multirow[t]{4}{*}{ Missing } & System & 12 & 10.9 \\
\hline & & 110 & 100.0 \\
\hline & & Frequency & Percent \\
\hline & YES & 3 & 2.7 \\
\hline \multirow[t]{2}{*}{ USE OF TOBACCO/SNUFF } & NO & 107 & 97.3 \\
\hline & Total & 110 & 100.0 \\
\hline
\end{tabular}

Table 6. Gross appearance of the cervix.

\begin{tabular}{cccc}
\hline & & Frequency & Percent \\
\hline & HEALTHY & 104 & 94.5 \\
GROSS APPEARANCE & GROWTH & 5 & 4.5 \\
OF THE CERVIX & HYPEREMIA & 1 & .9 \\
& Total & 110 & 100.0 \\
\hline
\end{tabular}

Table 7. Pap smear result.

\begin{tabular}{cccc}
\hline & & Frequency & Percent \\
\hline & INSUFFICIENT & 3 & 2.7 \\
& INFLAMMATORY & 50 & 45.5 \\
PAP SMEAR RESULT & NEGATIVE & 50 & 45.5 \\
& ${ }^{*}$ LSIL & 5 & 4.5 \\
& ${ }^{*}$ HSIL & 2 & 1.8 \\
& Total & 110 & 100.0 \\
\hline
\end{tabular}

${ }^{\star}$ LSIL; Low Squamous Intra-epithelial Neoplasia. ${ }^{*}$ HSIL; High Intra-epithelial Neoplasia.

Table 8. Cytology grade.

\begin{tabular}{lccc}
\hline & & Frequency & Percent \\
\hline & NO LESION & 103 & 93.7 \\
CYTOLOGY GRADING & LESION PRESENCE & 7 & 6.3 \\
& Total & 110 & 100.0 \\
\hline
\end{tabular}


Table 9. Preinvasive lesion.

\begin{tabular}{ccc}
\hline & Frequency & Percent \\
\hline LSIL & 5 & $71.4 \%$ \\
HSIL & 2 & $28.6 \%$ \\
\hline
\end{tabular}

\section{Discussion}

Cervical cancer though highly preventable, has continued to be a major cause of morbidity and mortality amongst women in the developing countries with many of them dying at their prime [1].

The prevalence rate of preinvasive cervical lesion following Pap smear from this study was $6.3 \%$. This figure is similar to the previous studies done amongst pregnant women in Nigeria which was 6\% [4]. It is also similar to the findings from the study done in Thailand though using VIA which was 6.7\% [5]. It is also similar to the findings from the studies conducted amongst non-pregnant women in Nigeria. This further confirms the fact that cervical cytology conducted during pregnancy is as reliable as those conducted when the individual is not pregnant [9]. In Maiduguri, Northern Nigeria, the prevalence of $7.8 \%$ was obtained following review of Pap smear over 15-year period amongst women attending gynaecologic clinic [10]. The prevalence of pap-smear reported in the developed world is between $0.5 \%$ - 3\% [11] [12] [13] [14]. However, reports from Turkey and Brazil had lower prevalence rate of $0.9 \%$ and $1.9 \%$ respectively [5].

The age range from this study is between 15 - 44 years and this represents the reproductive age group since the study was carried out amongst pregnant women. This age range is in keeping with other previous studies done in Zaria, Nigeria [4], Thailand [5] and Turkey [6].

Majority of the women had secondary education $54.5 \%$ which ordinarily should have impacted on their knowledge, awareness and practice of cervical screening but this was rather to the contrary. This result differed from the findings from the previous studies done in the northern Nigeria were majority of the women did not have formal education [4] [10].

The knowledge, awareness and practice of Pap smear screening from this study were rather poor. The reason for this could be multifactorial ranging from poverty, illiteracy, ignorance and lack of effective cervical cancer screening program in the state. This is similar to the findings from the previous studies done in the developing countries [1] [4] but differs from the studies done in developed countries [3] [8].

Most women from this study had positive risk factors for cervical cancer such as early coitarche, high risk partners, previous history of STI, previous history of vaginal warts, HIV infection, smoking and poor barrier contraceptive use. This might have contributed to the high prevalence rate found in the study. This is similar to the findings from the previous studies done in Nigeria and other de- 
veloping countries [1] [4] [5].

Despite the fact that most women had apparently healthy looking cervix (94.5\%), majority of the pap smear findings showed inflammatory smear (45.5\%) and preinvasive smear in $6.3 \%$. This is similar to the findings in the previous studies done in Nigeria [1] [4], and also in studies done in Turkey and India [6]. This means that apparently healthy looking cervix does not necessarily connote a disease free cervix, hence, this underscores the importance of routine cervical screening.

The incidence of LSIL $71.4 \%$ compared to HSIL $28.6 \%$ from this study suggests the ratio of 7:3. This finding is similar to the ratio found in the study done amongst pregnant women in Zaria, northern Nigeria where they recorded the same ratio [4]. The regression rate of these lesions was not followed up in this study, however, the Zaria study showed a regression rate of $50 \%$. Studies done on course of preinvasive cervical lesion in developed countries showed surprisingly high rate of regression from HGSIL to LGSIL and from LGSIL to negative smears during pregnancy and delivery [15].

\section{Conclusion}

The pap-smear findings among pregnant women in Abakaliki, Nigeria showed that the pre-invasive lesion of the cervix is relatively common. Since cervical cytology conducted during pregnancy is as reliable as those conducted when the individual is not pregnant, pap smear should be made routine for all pregnant women.

\section{Limitation of the Study}

This study was limited by finance. Hence, it was not able to study the pattern of pap smear in post natal period in this group of women.

\section{Conflict of Interest}

There is no conflict of interest to declare.

\section{Funding}

None.

\section{References}

[1] Bruni, L., Barrionuevo-Rosas, L., Albero, G., Serrano, B., Mena, M., Gómez, D., Muñoz, J., Bosch, F.X. and de Sanjosé, S. (2016) ICO Information Centre on HPV and Cancer (HPV Information Centre). Human Papillomavirus and Related Diseases in Nigeria, Summary Report.

[2] Khandelwal, P., Javadekar, D. and Kumbhar, S. (2016) Comparative Study of Pap Smear between Pregnant and Non Pregnant Women. International Journal of Scientific Research, 5, 368-369.

[3] Canfell, K., Sitas, F. and Beral, V. (2006) Cervical Cancer in Australia and the United Kingdom: Comparison of Screening Policy and Uptake and Cancer Incidence 
and Mortality. The Medical Journal of Australia, 185, 482-486.

[4] Fadimatu, B., Muhammad, A.A. and Saad, A.A. (2017) The Prevalence and Course of Preinvasive Cervical Lesions during Pregnancy in a Northern Nigerian Teaching Hospital. Asian Pacific Journal of Cancer Prevention, 16, 74-80.

[5] Jiraporn, L., Panya, S., Wineeya, S., Kornkarn, B., Komsun, S. and Yosapon, L. (2016) Prevalence and Risk Assessment of Cervical Cancer Screening by Papanicolaou Smear and Visual Inspection with Acetic Acid for Pregnant Women at a Thai Provincial Hospital. Asian Pacific Journal of Cancer Prevention, 17, 4163-4167.

[6] Ayten, D. (2012) Pap Smear Screening Results for Turkish Pregnant Women. Asian Pacific Journal of Cancer Prevention, 13, 5835-5838. https://doi.org/10.7314/APJCP.2012.13.11.5835

[7] Kiguchi, K., Bibbo, M., Hasegawa, T., Kurihara, S., Tsutsui, F. and Wied, G.L. (1981) Dysplasia during Pregnancy: A Cytologic Follow-Up Study. Journal of Reproductive Medicine, 26, 66-72.

[8] Solomon, D., Davey, D., Kurman, R., Moriarty, A., O’Connor, D., Prey, M., et al. (2002) The 2001 Bethesda System: Terminology for Reporting Results of Cervical Cytology. JAMA, 287, 2114-2119. https://doi.org/10.1001/jama.287.16.2114

[9] Vural, E., Gonenc, L. and Aka, N. (2004) Antenatal Kontrollerde Pap Smear Taramasi Vesonuclari. Türkiye Aile Hekimligi Dergisi, 8, 111-115.

[10] Audu, B.M., Elnafaty, A.U. and Pindiga, H.U. (2007) Prevalence of Abnormal Cervical Smears from Sporadic Screening in a Gynaecologic Clinic. Nigerian Medical Practitioner, 5, 114-118.

[11] Serati, M., Uccella, S., Laterza, R.M., Salvatore, S., Beretta, P., Riva, C., et al. (2008) Natural History of Cervical Intraepithelial Neoplasia during Pregnancy. Acta Obstetricia et Gynecologica Scandinavica, 87, 1296-300. https://doi.org/10.1080/00016340802482986

[12] Massad, L.S., Einstein, M.H., Huh, W.K., Katki, H.A., Kinney, W.K., Schiffman, M., et al. (2013) 2012 Updated Consensus Guidelines for the Management of Abnormal Cervical Cancer Screening Tests and Cancer Precursors. Obstetrics \& Gynecology, 121, 829-846. https://doi.org/10.1097/AOG.0b013e3182883a34

[13] Jones, B.A. and Davey, D.D. (2000) Quality Management in Gynecologic Cytology Using Interlaboratory Comparison. Archives of Pathology \& Laboratory Medicine, 124, 672-681.

[14] Ahdoot, D., Van Nostrand, K.M., Nguyen, N.J., Tewari, D.S., Kurasaki, T., Di Saia, P.J., et al. (1998) The Effect of Route of Delivery on Regression of Abnormal Cervical Cytologic Findings in the Postpartum Period. American Journal of Obstetrics and Gynecology, 178, 1116-20. https://doi.org/10.1016/S0002-9378(98)70310-2

[15] Hunter, M.I., Tewari, K. and Monk, B.J. (2008) Cervical Neoplasia in Pregnancy, Part 1: Current Treatment of Pre Invasive Disease. American Journal of Obstetrics and Gynecology, 199, 3-9. https://doi.org/10.1016/j.ajog.2008.04.010 


\section{Appendix 1}

\section{Cervical cancer screening in pregnant women}

1. Phone number:

2. Age:

3. Parity:

4. Tribe: Igbo [ ], Hausa [ ], Yoruba [ ], Others (specify).

5. Religion: Christian [ ], Islam [ ], ATR [ ]

6. Level of education: Primary [ ], secondary [ ], Tertiary [ ], No formal [ ]

7. Occupation: Farmer [ ], Trader [ ], Teacher [ ], Others [ ]

8. Marital status: Married [ ], Single [ ], Divorced [ ], Separated [ ], Widow [ ]

9. State of origin: Ebonyi [ ], Enugu [ ], Anambra [ ], Others (specify).........

10. Weight:

11. Height:

12. LMP:

13. Age at marriage:

14. Age at first intercourse:

15. HIV status: Negative [ ], Positive [ ]

16. Gestational age: 1st trimester [ ]. 2nd trimester [ ], 3rd trimester [ ].

17. Awareness of cervical cancer: Yes [ ], No [ ]

18. Awareness of cervical cancer screening: Yes [ ], No [ ]

19. If yes from where? Hospital [ ], Friend [ ], Media [ ], Others (specify)......

20. Have you ever been screened: Yes [ ], No [ ]

21. If no, why? Cost [ ], I don't know where to do it [ ], It's not necessary [ ], No time [ ], Others (specify)

22. Vaginal itching: Yes [ ], No [ ]

23. Vaginal bleeding: Yes [ ], No [ ]

24. Post coital bleeding: Yes [ ], No [ ]

25. Previous use of contraception Yes [ ], No [ ]

26. If yes state method: IUCD [ ], Barrier [ ], Withdrawal [ ], OCP [ ], Injectables [ ], Others (specify)

27. Use of tobacco/snuff: Yes [ ], No [ ]

28. Previous history/treatment for STD: Yes [ ], No [ ]

29. Previous history/treatment of STD in partner: Yes [ ], No [ ]

30. Total number of lifetime sexual partners:

31. FGM: Absent [ ], Type 1 [ ], Type 2 [ ], Type 3 [ ]

32. Genital warts: Yes [ ], No [ ]

33. Gross appearance of the cervix: Healthy [ ], Growth [ ], Hyperaemia [ ], Erosion [ ], Others (specify)

34. Contact bleeding: Yes [ ], No [ ]

35. Pap smear result: Insufficient sample [ ], Inflammatory [ ], Negative[ ], ASC-US [ ], LSIL [ ], LSIL [ ], SC Carcinoma [ ], AGC [ ], AIS [ ], AGUS [ ], Others (specify).

36. Will you recommend this procedure for other pregnant women: Yes [ ], No [ ], Maybe [ ] 